\title{
O PÓS-ESTRUTURALISMO E SUAS INFLUÊNCIAS NAS PRÁTICAS EDUCACIONAIS: A PESQUISA, O CURRÍCULO E A "DESCONSTRUÇÃO"
}

\author{
Guilherme Lima CARDOZO \\ (Pontifícia Universidade Católica - PUC-Rio) \\ guilhermecardozo0@hotmail.com
}

Resumo: Este artigo, que traz o Pós-Estruturalismo como viés a ser explorado pedagogicamente, visa a promover uma reflexão acerca das práticas educacionais, sejam elas pautadas em teorias positivistas, sejam em teorias críticas, demonstrando como as ideias pós-estruturalistas, em especial a "desconstrução", proposta por Jacques Derrida, possibilita uma nova epistemologia no campo do ensino.

Palavras-chave: Pós-Estruturalismo. Currículo. Desconstrução. Prática educacional.

\section{POST-STRUCTURALISM INFLUENCES ON EDUCATIONAL PRACTICES: RESEARCH, CURRICULUM AND DICONSTRUCTION}

\begin{abstract}
This article, which suggests how poststructuralism can be explored pedagogically, aims to promote a debate about educational practices, either guided by positivist theories or those guided by critical theories, demonstrating how poststructuralist ideas, "deconstruction" especially, proposed by Jacques Derrida, enable the rise of a new epistemology in the field of education.
\end{abstract}

Keywords: Poststructuralism. Curriculum. Deconstruction. Educational practices. 


\section{Introdução}

Quando conversamos sobre o futuro do país, quase sempre recaímos em questionar os modelos vigentes na educação de base. Essa crítica à educação por muitas vezes permanece em solo superficial, em forma de censura à maneira como os professores lidam com os alunos em sala de aula, ou como esses mesmos alunos desvalorizam os compêndios oferecidos pela escola, e até como a própria escola e seus funcionários negligenciam o fator "aprendizado" por parte de seu corpo discente. Uns mais politizados condenarão o sistema, que, ocupado em garantir seus lucros, não se preocupa com a educação brasileira. Contudo, independentemente de erradas ou não as observações sobre educação que permeiam o senso comum, a crítica a que atine este trabalho se dá no campo de um objeto denominado currículo, as questões subliminares que envolvem o seu desenvolvimento, a que teorias está vinculado, como se dão as pesquisas interligadas a determinados paradigmas e, principalmente, quais os movimentos existentes na contramão do modelo estabelecido.

Precisamente aqui dialogaremos com alguns prismas acerca da ciência da educação, os quais se configuram divergentes em bastantes pontos, entretanto, em alguns casos, confluem entre si. Primeiramente analisaremos o paradigma positivista na educação, suas implicações, suas crenças, e, mormente, como, durante tanto tempo, manteve-se modelo padrão de pesquisa, de currículo, de ensino, e, consequentemente, de aprendizado, haja vista envolver todo o processo de conhecimento filosófico, desde a Antiguidade Clássica até os dias de hoje - queiram ou não. Em contrapartida, veremos de que maneira as chamadas teorias críticas rompem com o modelo tradicional de ensino, e buscam, por meio de um corte epistemológico consideravelmente profundo, recolocar no centro da teoria e da prática educacionais fatores preponderantes, tais como o sujeito, a sociedade e suas ações, a cultura e a história, estes relegados ao esquecimento em nome de uma ciência objetiva e neutra.

Por fim, pelo fato de ser objeto de meu interesse investigativo, cuidaremos sobre as influências mais marcantes infligidas pelo Pós-Estruturalismo nas discussões sobre pesquisa, seja quantitativa ou qualitativa, currículo e linguagem, 
mostrando de que forma noções como as de "verdade", "sujeito", "desconstrução" e "différance", aparecem nos construtos dos pesquisadores críticos, construtivistas e de métodos participativos. Não obstante, de extrema importância também é traçar as ideias que influenciaram a prática antiessencialista, herança de uma crítica à metafísica iniciada por Friedrich Nietzsche, continuada por Sigmund Freud, e, especificamente no campo educacional, tão bem incorporada por nomes brilhantes como Vygotsky e Freire, os quais trouxeram a importância de se pensar a subjetividade como objeto de pesquisa dentro da educação.

Nosso trabalho iniciar-se-á com um breve histórico do paradigma positivista, herdeiro de uma filosofia preocupada com o universalismo, com a verdade essencial, intricada com uma prática científica onde as ações humanas não possuíam estatuto de objeto de análise: o modelo representacionista de mundo, em detrimento do paradigma da práxis, onde a busca por uma verdade exterior ao objeto se tornará o modelo de se fazer ciência. Esse será o ponto de partida de nossa análise, bem como, mais tarde, elemento passível de crítica.

\section{A filosofia platônico-aristotélica e seus satélites}

Toda a tradição educacional positivista, a qual busca, através de métodos objetivos, chegar a uma série de resultados mensuráveis, reflete-se na noção de currículo exposta por Bobbitt, baseada no processo de industrialização, presente à época:

O currículo é visto como um processo de racionalização de resultados educacionais, cuidadosa e rigorosamente especificados e medidos (...) o currículo é supostamente isso: a especificação precisa de objetivos, procedimentos e métodos para a obtenção de resultados, que possam ser precisamente mensurados (BOBBIT apud SILVA, 2005, p. 12).

Essa prática educacional é herdeira de uma noção filosófica do conhecimento concebida pelos gregos clássicos, primeiramente com Platão, e posteriormente com seu discípulo Aristóteles. Ambos elaboraram verdadeiros tratados que influenciaram praticamente todos os setores da ciência ocidental.

Em sua obra $A$ República, Platão falou sobre uma verdade essencial, perfeita, presente em um mundo ideal. Nós, através da mimeses, apenas tentamos transmitir essa essência às coisas, através da linguagem, 
imperfeitamente. Essas verdades pertencentes ao mundo das ideias possuíam natureza perene e imutável, o que já se configurava como uma maneira de resolver o problema dos universais.

Aristóteles também se apoiava nesse ideário da universalidade, e, logo na abertura de sua obra De Interpretatione, vai afirmar que os sons emitidos pela fala são símbolos das afecções da alma, e os caracteres escritos, ou seja, as palavras são os símbolos dos sons emitidos pela fala; e apesar de fala e escrita não serem as mesmas em toda a parte, as paixões da alma assim o são, como o são também os objetos dos quais essas paixões são representações ou imagens ( $D e$ Interpretatione, 16a 1). ${ }^{1}$

A questão é que ambos legitimaram o conhecimento humano como uma imitação imperfeita de algum conhecimento essencial, superior e perfeito, o qual se configuraria como "o conhecimento", possuidor de uma verdade ontológica e epistemológica. Esse pensamento permeou e muito o desenvolvimento da investigação científica até o século XIX, quando, principalmente com Nietzsche, iniciou-se um rompimento com essa filosofia positivista. As teorias do currículo, não diferentemente, obedeciam a essa tradição metafísica, pois supunham a existência de uma coisa transcendental chamada "currículo", existindo fora do sujeito e esperando para ser descoberta. A própria noção de teoria sofre influência direta da filosofia platônico-aristotélica:

Em geral, está implícita, na noção de teoria, a suposição de que a teoria "descobre" o "real", de que há uma correspondência entre a "teoria" e a "realidade". De uma forma ou de outra, a noção envolvida é sempre representacional, especular, mimética: a teoria representa, reflete, espelha realidade (SILVA, 2005, p. 11).

\section{O paradigma positivista}

Antes da mencionada virada intelectual do século XIX, perdurava nos campos das ciências humanas o paradigma da racionalidade, em detrimento de qualquer intervenção emocional, ideológica, cultural ou histórica, revestida pela máxima cartesiana cogito, ergo sum, a qual patenteou o ideário de que o homem,

\footnotetext{
${ }^{1}$ Em algumas traduções do "De Interpretatione" de Aristóteles, como por exemplo a do Prof. Dr. Emmanuel Carneiro Leão, fala-se em "disposições da alma"; já em C.W.A. Withaker, tem-se afecções da alma (pensamentos).
} 
através da razão pura, poderia chegar a um cientificismo objetivo, neutro, desvelando as verdades necessárias ao estabelecimento do que se chamou ciência racional. Esse modelo cartesiano também envolveu a prática educacional, onde se convencionava uma ontologia "real" - como o mundo real de Platão porém inteligível; uma epistemologia dualista/objetivista, em busca das descobertas verdadeiras; uma metodologia experimental/manipuladora, onde vigora a verificação de hipóteses, por métodos, sobretudo, quantitativos, cujo objetivo investigativo seria a explicação por predição e controle; supõe-se a natureza do conhecimento como mera verificação de hipóteses estabelecidas como fatos ou leis, e seu acúmulo se dá por acréscimo, como "blocos de construção" que se somam ao "edifício do conhecimento". O modelo positivista é possuidor de uma ética extrínseca, cujos cientistas possuem uma voz desinteressada, apenas como um informante dos tomadores de decisões: eles não transformam, não refletem, não participam, pois são fruto de um treinamento técnico e quantitativo, permeado por teorias substantivas (GUBA \& LINCOLN, 2006, p. 172).

O paradigma positivista é derivado necessário de um pensamento essencialista, cuja axiologia admite um saber proposicional a respeito do mundo que, por si só, é uma finalidade e possui valor intrínseco. Daí os pesquisadores, os professores, todos os envolvidos nessa teia apenas terem uma existência passiva diante do modelo teleológico de pesquisa, onde o saber estaria localizado em algum lugar, e nós apenas deveríamos ser instruídos corretamente a fim de captá-lo. Sob esse ponto de vista, a ação e a subjetividade são vistas como uma espécie de defesa, sendo consideradas uma ameaça à validade e à objetividade da pesquisa. Entretanto, num ambiente em que o conceito de verdade configurase tão variável, e o de certo e errado cada vez mais cambaleia, é-se possível uma ciência neutra e desinteressada?

\section{Controvérsias e confluências}

Segundo Guba \& Lincoln, vê-se hoje uma interessante disputa por legitimidade entre os paradigmas de pesquisa pós-modernos (teoria crítica pósmodernista e construtivismo) e os paradigmas positivista e pós-positivista, em 
busca de hegemonia intelectual e paradigmática, de certa forma pertencente à segunda corrente.

Eles expõem três motivos principais para que a ciência de pesquisa convencional venha, no mínimo, dividindo espaço com as teorias críticas: o primeiro é o interesse crescente que leitores familiarizados com a literatura sobre métodos e paradigmas demonstram acerca de novas possibilidades de se fazer pesquisa; segundo, que profissionais já estabelecidos dentro do campo de pesquisa quantitativa buscam aprender mais sobre as abordagens qualitativas, devido a uma nova demanda nessa linha; por fim, há uma "explosão" - termo usado pelos autores acima - de trabalhos na área qualitativa de pesquisa (GUBA \& LINCOLN, 2006, p.169).

Apenas nessas primeiras linhas, podemos já contemplar uma reconfiguração das estruturas positivistas - ou pelo menos um movimento claro nessa direção - onde uma guinada das ciências sociais em direção a uma prática e a uma teorização mais interpretativa, pós-moderna e criticalista parece inevitável. A crise da representação, tão apregoada por filósofos como Nietzsche, Freud e Marx, e encarnada pelo movimento pós-estruturalista, principalmente na França dos anos sessenta, dá, então, seu tom nas teorias de pesquisa na área da educação, onde, talvez, ela mais se faça necessária e urgente.

Uma frase importante no texto de Guba \& Lincoln mostra como urge um novo tratamento dos métodos de pesquisa: "a metodologia investigativa não pode mais ser tratada como um conjunto de regras ou de abstrações universalmente aplicáveis" (p. 170), ou seja, não há mais como negar a participação do sujeito, da sociedade, da cultura e da história na elaboração de metodologias suficientemente aplicáveis à educação, fazendo-se mister o rompimento com o protótipo de universalidade proposto desde a Antiguidade Clássica, e, por incrível que pareça, pungente nos modelos positivistas de pesquisa, conforme já mencionamos nas segunda e terceira seções deste artigo.

Nesse texto fala-se sobre uma "nova consciência", que emerge do reconhecimento dos valores individuais e sociais, fazendo com que paradigmas diversos dialoguem uns com os outros, fazendo surgir das controvérsias um espaço intelectual, teórico e prático para uma confluência, um consenso. Segundo Laurel Richardson, essas categorias presentes nos paradigmas mais diversos 
"são mutáveis (...) até mesmo ao escrever[mos], os limites entre os paradigmas estão se modificando", (ibidem, p. 172) o que significa um rompimento relativo com a estabilidade dos parâmetros universais de pesquisas, os quais, objetivos por natureza, são insensíveis às mais diferentes práticas pungentes no seio da vida humana.

Os autores não partem dos princípios absolutistas para julgar que critérios sejam os mais viáveis para se julgar a validade e a realidade dos dados, mas levam em consideração três aspectos preponderantes: esse julgamento deve ser proveniente de um consenso da comunidade, dentro da qual observamos aquilo que diz respeito ao real, ao útil e ao que tem sentido para a mesma. Revela-se aqui uma postura construtivista social/construcionista, onde prevalece a ação dos indivíduos dentro da sociedade como o fenômeno social a ser delineado.

Um ponto interessante é o reconhecimento de que a axiologia deva fazer parte das dimensões filosóficas fundamentais básicas da proposta do paradigma, haja vista que esse procedimento auxilia e muito na concepção da ética dentro do paradigma, e não fora dele. Importante também o papel da espiritualidade na investigação humana, por conduzir a uma inquieta necessidade de liberar-se da opressão, ansiando pela libertação do espírito humano, o que aproxima, por exemplo, paradigmas construtivistas de investigadores participativos, e ainda dos críticos de ambas, pois tais preocupações com a liberdade do espírito humano é comum a todos esses ramos. A consideração dos axiomas dentro dos paradigmas faz com que o espiritual encontre a investigação social, conforme Reason, Lincoln e Denzin propuseram.

A questão é: no que concerne aos paradigmas de pesquisa, deve-se romper inelutavelmente com um em prol de outro, ou tentar misturar elementos de um paradigma dentro de outro? A comensurabilidade entre eles é algo muito relativo, haja vista abordagens por vezes inteiramente contraditórias, daí os autores afirmarem essa possibilidade de comensurabilidade cautelosamente.

Quanto à ação, a divergência entre positivistas e interpretativistas fica mais clara: enquanto para os primeiros ela contamina os resultados da pesquisa, pois se configura como uma forma de subjetividade, maculando o propósito de objetividade científica, para os últimos - e meu ponto de vista é exatamente este - é uma consequência significativa dos processos de investigação. Nos modelos 
construtivista e participativo, esse processo é uma tentativa de compromisso político e ético para com os participantes, entendendo a linguagem dentro da práxis social, não mais como mácula a uma suposta objetividade, característica de uma rigorosa investigação neutra, mas como "forma de vida", nos termos Wittgeinstenianos, pois, conforme o mesmo proclama: "os significados não estão em algum ponto fixo e transcendental do universo, prontos a serem capturados e aplicados invariavelmente, eles estão no uso dentro do jogo social" (WITTGENSTEIN, 2012, § 43).

O afastamento do subjetivo é uma herança clara da filosofia clássica, inauguradora da metafísica da presença, para quem há uma essência por detrás das coisas, uma verdade absoluta, ou, nas palavras de Aristóteles, um padrão imutável nas afecções de nossa alma, por mais que as línguas e as escritas difiram entre os povos. Para os positivistas, herdeiros indiretos dessa linha de raciocínio, o controle do estudo deve estar definitivamente afastado da voz da reflexividade e dos assuntos concernentes à representação textual, pois ameaçam o rigor da objetividade e da validade, ao passo que para investigadores participativos e construtivistas há um desejo de ver os participantes da pesquisa se envolverem cada vez mais, enxergando o controle como forma de emancipação, compensando desigualdades de poder, a fim de dar alguma voz aos que, porventura, fossem marginalizados, apregoando a impossibilidade de separação entre o conhecimento e o pesquisador, refutando qualquer possibilidade de plena neutralidade na pesquisa.

Um ponto muito rico em discussão é acerca dos fundamentos da verdade e do conhecimento: o conceito de verdade, para os positivistas, logicamente parte de um essencialismo platônico. Para estes, como já dito, não há dúvidas de que exista uma realidade "real" no exterior, além da imperfeita percepção humana desta, aliada à herança direta do pensamento cartesiano, o qual proclamava que o domínio objetivo é independente das experiências subjetivas:

O conhecimento real limita-se aos objetos e às relações entre eles existentes no domínio do tempo e do espaço. A consciência humana, que é subjetiva, não está acessível à ciência, não podendo ser, portanto, verdadeiramente conhecida (GUBA \& LINCOLN, 2006, p. 180). 
Esse afastamento do sujeito em relação às pesquisas científicas será rechaçado por Vygotsky, estudioso do campo psicológico dentro da educação, o qual afirmou que "Antes tínhamos a mente sem comportamento. Agora temos o comportamento sem a mente. Em ambos os casos, nós temos mente e comportamento compreendidos como dois fenômenos distintos e separados" (VYGOTSKY apud FREITAS, 2000, p. 84), declaração esta que embasava sua insistência em que consciência e comportamento fossem objetos de pesquisa psicológica, pois, para ele, a escola era o próprio lugar da psicologia, mas não aquela que não levasse em conta fatores socioinstitucionais, cujos dados recolhidos eram analisados no quadro de uma pedagogia a-histórica e a-social, todavia aquela que concebia que as funções psíquicas do indivíduo são constituídas na medida em que são utilizadas, sempre na dependência do legado cultural da humanidade, da qual ela é parte ativa. Freud, que revolucionou a ciência da linguagem, tendo como referência o sujeito e suas implicações, também criticou o afastamento destes de tudo o que se ousou chamar ciência. Em contrapartida, fundou sua Psicanálise no estudo denodado da subjetividade, e nas implicações das características subjetivas mais profundas no mundo objetivo.

Retomando a discussão entre os paradigmas, os teóricos e críticos também dialogam com interessantes pontos de vistas que buscaram romper com o modelo essencialista do positivismo, quais sejam, o de Saussure, trazendo a noção de língua como sistema, funcionando dentro de um conjunto de relações linguísticas, e não ontológicas, exteriores; além de outras, como as contribuições desconstrutivas da teoria literária, que, como o nome sugere, visa a desligar os textos de qualquer sentido essencialista, recolocando-os dentro dos contextos sociais e históricos do autor e do leitor.

Isso remete ao termo antifundacionalismo (GUBA \& LINCOLN, 2006, p. 182), tendência vista nos construtivistas, que consiste na recusa de qualquer adoção a padrões permanentes e invariáveis, por meio dos quais a verdade pode ser conhecida universalmente. Lincoln fala de uma verdade insurgente da relação entre membros de uma sociedade, negociações do que se estipula como verdade e falsidade. Para isso, podemos tomar o conceito nietzschiano de verdade como uma necessidade que 0 homem possui para viver em comunidades, 
estabelecendo um "tratado de paz", obtido por meio do intelecto para a preservação do grupo, o qual

traz consigo algo que parece ser o primeiro passo para alcançar aquele enigmático impulso à verdade. Assim, a partir daí fixa-se aquilo que doravante deverá ser "verdade", ou seja, inventa-se uma designação uniformemente válida e obrigatória para as coisas, e a legislação da linguagem estabelece também as primeiras leis da verdade: assim se origina, pela primeira vez, o contraste entre verdade e falsidade (NIETZSCHE, 2000, p. 176).

Sobre a questão da validade dos dados da pesquisa, gostaria de me apegar ao conceito de validade como resistência e transgressão. A proposta de Laurel Richardson que, através da metáfora do cristal, chega a essa validade, nos fornece material interessante: primeiro rompe com a ideia de relação entre validade e a figura do triângulo - rígido, fixo e bidimensional, o que remete às velhas dicotomias metafísicas - em prol da figura do cristal, o qual combina simetria e substância com uma infinita variedade de formatos, substâncias, transmutações, multidimensionalidades e ângulos de aproximação. Entretanto, apesar de mudar, crescer e se alterar, o cristal não é amorfo: sua forma, ou seja, sua validade, dependerá do ângulo de visão. Assim, desconstrói-se o ideário de uma verdade única e universalmente aplicável a todos, entrelaçando sujeito e objeto na pesquisa (GUBA \& LINCOLN, 2006, p. 186).

Tal qual Richardson, Patti Lather também proporá uma validade transgressiva, arrojada, rompendo com o status quo e almejando uma validade neopragmática, promovendo a heterogeneidade e recusando a revelação, num prisma onde ética e epistemologia se reconciliam: "Juntas, essas validades formam um caminho para interromper, romper e transformar a 'pura' presença em uma presença perturbadora, mutável, parcial e problemática" (ibidem). Esse adiamento/diferimento decorrente dessa perturbação do significado, remete-nos à desconstrução derridiana bem como à ideia de différance, criada por Derrida. Considerando a crise da representação, como aborda Lather, o filósofo francês negará que haja um ponto de parada para o significado, propondo o jogo livre dos significantes, o que transforma completamente a ideia de uma presença no sistema. 


\section{Pós-Estruturalismo e seus reflexos na prática educacional}

Conforme Lather, as teorias pós-estruturalistas ofereceram um rico campo de reflexão para a prática de pesquisa educacional, promovendo, como já se disse, a heterogeneidade, buscando uma validade rizomática, uma forma de comportamento por meio de múltiplas aberturas, recusando a mera revelação de um conhecimento prévio, o qual esteja em "algum lugar do universo" pronto para ser capturado e aplicado como verdade (LATHER, 1993, p. 680). Depois do pósestruturalismo, muitas oposições clássicas como as de sujeito/objeto, ciência/ideologia, necessidade/contingência, fato/interpretação, langue/parole, verdadeiro/falso, foram violentamente abaladas, tornando o campo filosófico mais politizado. Segundo Tomaz Tadeu da Silva, o construto ideológico pósestruturalista amplia até mesmo o conceito de poder, muito enfatizado pela teoria crítica marxista, como proveniente não somente das esferas do Estado, mas presente "em toda parte. As teorias críticas não nos deixam esquecer, entretanto, que algumas formas de poder são visivelmente mais perigosas e ameaçadoras que outras" (SILVA, 2005, p. 147).

Bafejadas pelo rasgo epistemológico pós-estruturalista, as teorias críticas e pós-críticas de currículo deslocaram a ênfase dos conceitos meramente pedagógicos de ensino/aprendizagem para os conceitos de ideologia e poder como construtores da identidade social, o que, por exemplo, abriu o campo educacional para questões até então marginalizadas pelo sistema de ensino/aprendizagem/avaliação, cuja metodologia se baseia na análise de eficiência e objetivos mensurados, através de uma organização planejada. As teorias pós-críticas inovam ao trazer ao campo as questões de identidade/alteridade/diferença, considerando a subjetividade dentro da pesquisa científica, dando espaço às relações de saber e poder influenciando na cultura da sociedade, onde tensões advindas de gênero, raça, etnia e sexualidade trazem à tona o multiculturalismo. Sobre isso, o pós-estruturalismo trouxe colaboração ímpar à educação:

Nas teorias pós-críticas, entretanto, o poder torna-se descentrado. O poder não tem mais um único centro, como o Estado, por exemplo. O poder está espalhado por toda a rede social. (...) Em contraste com as teorias críticas, as teorias pós-críticas não limitam a análise do poder ao campo das relações econômicas do capitalismo. Com as teorias pós-críticas, o 
mapa do poder é ampliado para incluir os processos de dominação centrados na raça, etnia, no gênero e na sexualidade (SILVA, 2005, p. 148-9).

A noção de "desconstrução" como estratégia de leitura, trazida por Jacques Derrida, permitiu que os diversos campos da filosofia pudessem não somente inverter os binarismos existentes nos modelos positivistas, nos quais, tacitamente, há uma relação hierárquica entre os pares binários, mas "fazer implodir" esses pares um no outro, dentro de algo chamado por Derrida de "duplo gesto", sobre o qual nós falaremos agora.

\section{0 duplo gesto derridiano}

Já em fins deste trabalho, considero de muito bom tom trazer à discussão o chamado "duplo gesto" de Derrida, como uma das práticas desconstrucionistas de leitura - aqui, o próprio mundo, o próprio sujeito, como um texto. O primeiro gesto desconstrucionista consiste, inicialmente, na inversão das dicotomias clássicas: em lugar de Objeto/sujeito, o Sujeito/objeto; em vez de Significado/significante, o Significante/significado, dando ao termo marginalizado uma posição de superioridade ao que outrora fora visto como principal. Contudo, esse trabalho de inversão, para Derrida, não seria suficiente para que uma verdadeira desconstrução fosse realizada como êxito, pois o que se faria, de fato, seria trocar os polos binários, não destruindo a ideia dicotômica ali presente. Dessa forma, o segundo gesto desconstrucionista é o da "implosão": Derrida sugere que os elementos componentes dos pares binários se embaralhem um ao outro, fazendo com que experimentem uma alteridade violenta, a ponto de assumirem a perspectiva um do outro - passando a ser o mesmo: o mesmoutro - adiando, destarte, o ponto de parada das comparações paradigmáticas, diferindo o conceito do "ser" substancialmente, e ascendendo o "ser-com", o "ser-para", onde o significado da coisa não mais encontra um ponto pacífico de estabelecimento eis aí a ideia de différance.

No campo da prática educacional, podemos contemplar de maneira extraordinária a ideia do duplo gesto derridiano na obra de Parker J. Palmer, mais precisamente na seção onde trata sobre a vivência plena dos paradoxos no ensino/aprendizagem em sala de aula. Palmer inicia seu texto expondo o sintoma 
ocidental de se pensar por polaridades, sem o treinamento devido a escutar ambos os lados, guiados por uma tecnologia computadorizada - binária por excelência - adotando o sistema fragmentado de pensamento do either-or, em detrimento do que ele proporá mais adiante: o both-and:

What I want is a richer, more paradoxical model of teaching and learning than binary thought allows, a model that reveals how the paradox of thinking and feeling are joined (...) When a person is healthy and whole, the head and the heart are both-and, not either-or, and teaching that honors that paradox can help make us all more whole (PALMER, 2007, p. 64). ${ }^{2}$

Palmer, ao incorporar a seu discurso os paradoxos como algo a ser preponderante na prática pedagógica, usa dois exemplos para mostrar como 0 ser humano tem por natureza viver em paradoxos para ser completo: fala sobre o funcionamento de aparelhos eletrônicos, como a bateria, que, pela ligação dos pólos positivo e negativo, nos fornecem a energia necessária para a vida moderna; diz que o ser humano para viver precisa não somente inspirar o ar proveniente da natureza, mas também expirá-lo, devolvê-lo, de forma que as duas práticas não se separam, mas se imbricam. Dentro dessa lógica, Palmer mostra que alguns paradoxos, tratados dicotomicamente pela tradição curricular, são constitutivos de serem postos em diálogo: o primeiro paradoxo é entre a mente e o coração (leia-se razão e emoção), resultado de um pensamento cartesiano, herdeiro do essencialismo, o qual privilegia a racionalidade para se atingir 0 objetivo da ciência neutra: a verdade; o segundo é o que separa o fato do sentimento, não permitindo que a subjetividade "contamine" os fatos científicos; o terceiro entre teoria e prática, o qual impede que as ações da comunidade sejam objeto de estudo profícuo, e, em detrimento disso, traz questões à sala de aula às vezes sem qualquer interesse e influência direta na vida do corpo discente; o último paradoxo elencado por Palmer é entre ensinar e aprender, que consiste na prática docente surda aos anseios dos alunos, e de alunos que, consequentemente, escutam sem participar, sem construir o conhecimento.

\footnotetext{
${ }^{2} \mathrm{O}$ que eu quero é um modelo mais rico, mais paradoxal de ensino e aprendizagem do que o pensamento binário permite, um modelo que revela como o paradoxo do pensamento e sentimento são unidos (...) Quando uma pessoa é saudável e completa, a cabeça e o coração são both-and, não either-or, e ensino que honre esse paradoxo pode ajudar a tornar-nos a todos mais completos.
} 
De maneira brilhante, Palmer, segundo sugere o duplo gesto derridiano, não inverte o binarismo presente, no entanto, implode os elementos paradoxais um no outro, fazendo aproximarem-se texto acadêmico e práxis discente, abordagem teórica do aspecto histórico/cultural de cada subjetividade, mostrando que o ensino responsável e comprometido é aquele que se abre para a alteridade, sem medo dos riscos:

(...) I learn that my gift as a teacher is the ability to dance with my students, to co-create with them a context in which all of us can teach and learn, and that this gift works as long as I stay open and trusting and hopeful about who my students are (PALMER, 2007, p. 72).

\section{Considerações finais}

O legado pós-estruturalista para a educação, conforme vimos nas linhas deste trabalho, não foi somente desqualificar as práticas tradicionais de ensino, até porque os próprios estruturalistas, inclusive Derrida, assumem a impossibilidade de fugirmos inteiramente do modelo representacionista de linguagem, afinal, de uma forma ou de outra, somos ocidentais, crescemos nomeando e classificando as coisas, somos metafísicos por natureza. O que se propõe aqui é o salto de qualidade, o corte epistemológico com a passividade filosófica em nome de um projeto de construção conjunta de conhecimento e participação ativa nessa empreitada de ambos os elementos integrantes dos pares binários metafísicos. Uma educação que não almeje à mudança social e individual, que assuma a existência de um acabamento e que não conceba o sujeito e suas relações como parte da pesquisa, não pode mais vigorar com supremacia. Admitir isso configura-se uma grande falta de amor para conosco e para com o outro.

Encerrar este trabalho sem citar um ícone da pesquisa educacional como Paulo Freire seria de tamanha injustiça. Preferi fugir um pouco do protocolo e elencar citações as quais considero de suma importância para a discussão aqui realizada, e que garantem, indubitavelmente, um grand finale para este compêndio:

\footnotetext{
${ }^{3}$ Aprendi que meu dom como professor é a habilidade de dançar com meus estudantes, a fim de co-criar com eles um contexto dentro do qual todos nós podemos ensinar e aprender, e que esse dom funciona melhor à medida em que eu me mantenho aberto, confiante e esperançoso acerca de quem meus estudantes são.
} 
Não é possível fazer uma reflexão sobre o que é a educação sem refletir sobre o próprio homem.

O homem deve ser o sujeito de sua própria educação. Não pode ser o objeto dela.

Sem dúvida, ninguém pode buscar na exclusividade, individualmente. Esta busca solitária poderia traduzir-se em um ter mais, que é uma forma de ser menos. Esta busca deve ser feita com outros seres que também procuram ser mais e em comunhão com outras consciências (...).

O amor é uma tarefa do sujeito. Cada um tem o outro como sujeito de seu amor. Não há educação sem amor (FREIRE, 1979, p. 27).

\section{Referências bibliográficas}

ARISTÓTELES, Órganon. Da Interpretação. Bauru/S: Edipro, 2010.

FREIRE, Paulo. Alfabetização de adultos e conscientização. In Educação e Mudança. São Paulo: Ed. Paz e Terra, 1979.

FREITAS, Maria Teresa de Assunção. Vygotsky. In: Vygotsky e Bakhtin. Psicologia e Educação: um intertexto. São Paulo: Editora Ática, 2000.

GUBA E. G. \& LINCOLN, Y. Controvérsias paradigmáticas, contradições e confluências emergentes. In Denzin, Norman K.; Lincoln, Yvonna S. O planejamento da pesquisa qualitativa: teorias e abordagens. Porto Alegre: Artmed e Bookman, 2006.

LATHER, Patti. Fertile obsession: Validity after poststructuralism. Sociological Quarterly, vol. 34, n. 4, 1993, p. 673-693.

NIETZSCHE, Friedrich. Sobre a verdade e a mentira no sentido extramoral (1873). In: Obras Incompletas. São Paulo: Editora Nova Cultura, 2000.

PALMER, P. J. The Hidden Wholeness. In: The courage to teach: Exploring the Inner Landscape of a Teacher's Life. San Francisco: Jossey-Bass Publishers, 1998.

SILVA, Tomaz Tadeu da. Documentos de identidade: uma introdução às teorias do currículo. Belo Horizonte: Autêntica, 2005.

WITTGENSTEIN, Ludwig. Investigações filosóficas. Petrópolis: Ed. Vozes, 2012. 


\section{Bibliografia complementar}

ARROJO, Rosemary. O signo desconstruído: implicações para a tradução, a leitura e o ensino. Campinas: Pontes, 2003.

CULLER, Jonathan. Sobre a Desconstrução. Trad. Patrícia Burrowes. Rio de Janeiro: Editora Rosa dos Tempos, 1997.

DERRIDA, Jacques. A Escritura e a Diferença. São Paulo: Editora Perspectiva, 1995

Posições. Belo Horizonte: Autêntica, 2001.

PLATÃO. A República. São Paulo: Martins Claret, 2001. 
Artigo recebido em: 11 de outubro de 2013

Artigo aprovado em: 22 de novembro de 2013

\section{Sobre o autor:}

Guilherme Lima Cardozo é Mestre em Estudos da Linguagem pela Pontifícia Universidade Católica (PUC-Rio), Professor de Português Jurídico na Escola de Administração Judiciária (ESAJ) e integra o quadro dos funcionários do Tribunal de Justiça do Estado do Rio de Janeiro. Atualmente, cursa doutorado na PUCRio, na área de pesquisa de Linguagem, Sentido e Tradução, em Estudos da Linguagem. 